\title{
Implikasi Islam Untuk Pesan Iklan: Konteks Timur Tengah
}

\author{
Ulla Ramadini \\ STAIN Palangka Raya \\ ullaramadini@gmail.com \\ Fitriatun Najah \\ Darul Ulum Palangka Raya \\ ftriatunnajah009@gmail.com \\ Muhammad \\ STAIN Palangka Raya \\ muhammad1335@gmail.com
}

\begin{abstract}
Islam is the great religion and develops among the consumers all over the world. There is an evidence that the religious beliefs influence the consumers' behaviors and responses toward the message of the advertisement. The objective of the article is to present a framework in managerial decision making related to Islamic values toward the implication of illustrated advertisement in the context of Middle East. The recommendation is provided for international advertisement to develop the messages for the segmentation of Muslim consumers.
\end{abstract}

Keywords: Islam, message, middle east

\section{A. Pendahuluan}

Iklan merupakan salah satu instrumen penting yag digunakan oleh para produsen dalam rangka melakukan ekspansi produk-produk perusahaan meereka. Ekspansi produk diperlukan sebagai upaya untuk memenuhi salah satu siklus kegiatan ekonomi, yaitu distribusi. Tujuan dilakukan distribusi adalah agar bagaimana produk yang sudah diproduksi dapat sampai ke tangan konsumen sehingga mereka dapat memenuhi kebutuhannya.

Posisi sentral iklan mendorong sejumlah perusahaan baik dalam skala lokal, regional, nasional maupun multinasional merancang keputusan sedemikian rupa dalam mengiklankan produk-produk usaha mereka. Dalam lingkup perusahaan multinasional, misalnya mereka mempertimbangkan secara cermat keputusan yang dihadapi oleh perusahaan-perusahaan apakah membakukan atau 
mengadaptasi strategi iklan. Ini menjadi subyek perdebatan dan penelitian selama beberapa waktu terakhir ini.

Laroche dalam hasil investigasi empiriknya menemukan pentingnya masalah iklan bagi brand image sebuah perusahaan. Bahkan, ada kecenderungan bagi perusahaan untuk mencari bukti pentingnya mencari konfirmasi atau bertentangan dengan validitas konsep standar periklanan Internasional seperti yang dilakukan Onkvisit dan Shaw. Dalam sebuah penelitian perusahaan multinasional (MNC) konsumen pemasaran barang dan jasa di Arab Saudi, Kuwait, Arab Emirates, Lebanon dan Mesir, Melewar. menemukan bahwa manajer-manajer melihat Timur Tengah sebagai sebuah wilayah dengan budaya dan kepercayaan yang sama dan cenderung untuk mengikuti sebuah pendekatan standar sehubungan dengan tujuan iklan, posisi dan tema periklanan yang utama, keputusan cenderung dibuat di kantor pusat. Keputusan mengenai eksekusi kreatif dan strategi media sering dibuat secara lokal, namun menurut Hill dan James $^{1}$ dan Duncan, Ramaprasad ${ }^{2}$, pengambilan keputusan tentang iklan adalah fungsi dari tingkat kepercayaan anak perusahaan lokal.

Ironisnya, keputusan untuk membakukan lebih berkaitan dengan budaya perusahaan daripada dengan budaya pasar dan negara ${ }^{3}$. Laroche et al menemukan bahwa tingkat kontrol perusahaan multinasional (Multi National Corporate/MNC) atas anak perusahaan adalah penentu langsung standardisasi iklan ${ }^{4}$. Mereka menyimpulkan bahwa perusahaan multinasional perlu mengembangkan suatu orientasi belajar terhadap pasar luar negeri. Memahami kesamaan dalam posisi pasar, akrab dengan konteks asing dan berkembang bersama nilai-nilai dan kepercayaan di antara manajer perusahaan dan manajer HQ membuat perusahaan multinasional mengejar pendekatan standar untuk iklan. Tanpa belajar orientasi

\footnotetext{
${ }^{1}$ Hill, J.S. and W.L. James. 1990. "Effects of selected environmental and structural factors on international advertising strategy: an exploratory study." Current Issues and Research in Advertising 12: 135-154

${ }^{2}$ Duncan T. and J. Ramaprasad. 1995. "Standardized multinational advertising: the influencing factors." Journal of Advertising 24: 55-68

${ }^{3}$ De Mooij, M. 1998. Global Marketing and Advertising. Thousand Oaks, CA: Sage Publications, Inc.

${ }^{4}$ Laroche, M., V.H. Kirpalani, F. Pons and L. Zhou. 2001. "A model of advertising standardization in multinational corporations." Journal of International Business Studies 32: 249266
} 
ini, menurut Laroche et $\mathrm{al}^{5}$. standardisasi iklan perusahaan dengan didasarkan pada budaya cenderung ditantang oleh anak perusahaan lokal atau perwakilan. Keeratan hubungan antara perusahaan induk dengan budaya lokal memungkinkan seorang manajer di kantor pusat untuk memahami lebih baik apa yang harus dilakukan dalam aspek periklanan yang kreatif sesuai dengan standardisasi untuk menghindari kesalahan budaya. ${ }^{6}$

Budaya yang merupakan representasi dari cara orang berkomunikasi, melestarikan, dan mengembangkan pengetahuan mereka tentang sikap terhadap kehidupan dalam menafsirkan pengalaman mereka dan membimbing tindakan mereka ${ }^{7}$. Sumber dasar budaya ini menurut, Usunier $^{8}$ berasal beberapa dimensi yang mempengaruhinya seperti bahasa, kewarganegaraan, pendidikan, suku, agama, keluarga, jenis kelamin, sosial dan organisasi.

Artikel ini menfokuskan diri pada aspek agama. Tujuan artikel ini adalah untuk menjelaskan dan menggambarkan jenis pesan iklan yang mungkin cocok untuk satu kelompok agama Muslim dan kerangka pengambilan keputusan manajerial (lihat Gambar 1 dan Tabel 1) yang berhubungan nilai-nilai dasar Islam untuk disajikan. Tujuan mendasar adalah untuk memberikan kontribusi penting bagi perusahaan multinasional. Dengan cara ini, manajer dapat memahami situasi baik saat iklan ditujukan untuk pemirsa Muslim, standar dalam menkampanyekan iklan, penyesuaian iklan dengan budaya yang berbasiskan agama.

Dua puluh tahun yang lalu, Boddewyn ${ }^{9}$ membahas peran agama dalam regulasi. Selanjutnya, ada sedikit penelitian dilakukan tentang agama dan iklan. Hirschman ${ }^{10}$ mengusulkan dua alasan untuk ini. Pertama, mungkin agama terlalu sensitif dipakai untuk penyelidikan. Kedua, pengaruh agama ambigu. Baru-baru

\footnotetext{
${ }^{5}$ Laroche, M., V.H. Kirpalani, F. Pons and L. Zhou. 2001. "A model of advertising standardization in multinational corporations." Journal of International Business Studies

${ }^{6}$ Ricks, D.A. 1993. Blunders in International Business, Cambridge, MA: Blackwell Publishers.

${ }^{7}$ Geertz, C. 1973. The Interpretation of Cultures. New York: Basic Books.

${ }^{8}$ Usunier, J. 1993. International Marketing A Cultural Approach. Prentice Hall International (UK) Limited.

${ }^{9}$ Boddewyn, J.J. 1982. "Advertising regulation in the 1980s: the underlying global forces." Journal of Marketing Winter: 27-35.

${ }^{10}$ Hischman, E.C. 1984. "Religious affiliation and consumption processes." In Research in Marketing. Ed. J. Sheth. Greenwich, CT: JAI Press, 131-170
} 
ini peneliti dibayar untuk meningkatkan perhatian pada relevansi prinsip-prinsip agama untuk pengambilan keputusan bisnis secara umum (lihat, sebagai contoh, Rossauw 1994, Gould 1995, Beras 1999). Minat pada agama muncul dari penekanan hari pada etika dalam bisnis dan pertumbuhan globalisasi. Dalam dekade terakhir, studi tentang iklan dan agama menemukan bahwa komitmen keagamaan yang terkena dampak (1) respons Inggris Kristen dan Muslim untuk iklan $\mathrm{TV}^{11}$, (2) sikap laki-laki Saudi terhadap iklan $\mathrm{TV}^{12}$, dan (3) respon Bahraini Muslim untuk iklan $\mathrm{TV}^{13}$. Agama itu dapat menjadi mediator yang kuat di decoding pesan iklan ${ }^{14}$ perlunya menyarankan pemeriksaan lebih dekat pada agama dan iklan. Agama afiliasi memainkan peran penting dalam pembentukan sikap ${ }^{15}$, nilai pilihan ${ }^{16}$ dan terutama berkaitan dengan pertanyaan tentang mengapa orang mengkonsumsi ${ }^{17}$. Delener ${ }^{18}$ perbedaan ditemukan dalam keputusan pembelian mobil antara proses Yahudi dan Katolik dan menyimpulkan bahwa peningkatan pengetahuan terhadap perbedaan agama dalam pengambilan keputusan konsumen harus memiliki signifikan berdampak pada efektivitas strategi pemasaran global.

Agama selalu membantu menentukan apa yang tepat dan pas, dan sering melarang penggunaan tertentu (materialistis, seksual, dll). Beberapa elemen dari sebuah pesan iklan mungkin dirasakan oleh orang sebagai keyakinan terhadap agama mereka, sebagai perdebatan. Iklan dianggap kontroversial tidak akan efektif dalam menangkap perhatian orang atau perubahan sikap mereka terhadap

\footnotetext{
${ }^{11}$ Michell, P. and M. Al-Mossawi. 1995. "The mediating effect of religiosity on advertising effectiveness." Journal of Marketing Communications 1: 151-162.

${ }^{12}$ Al-Makaty, S.S., G.N. Van Tubergen, S.S.Whitlow, and D.A. Boyd. 1996. "Attitudes toward advertising in Islam.” Journal of Advertising Research 36: 16-26.

${ }^{13}$ Michell, P. and M. Al-Mossawi. 1999. "Religious commitment related to message contentiousness." International Journal of Advertising 18: 427-443

${ }^{14}$ Michell, P. and M. Al-Mossawi. 1995. "The mediating effect of religiosity on advertising effectiveness." Journal of Marketing Communications 1: 151-162.

${ }^{15}$ Hirshman, E.C. 1981. "American Jewish ethnicity: its relationship to some selected aspects of consumer behavior." Journal of Marketing 45 (Summer): 102-110.

${ }^{16}$ Keng, K.A. and C. Yang. 1993. "Value choice, demographics, and life satisfaction." Psychology and Marketing 10: 413-432

${ }^{17}$ Hischman, E.C. 1984. "Religious affiliation and consumption processes." In Research in Marketing. Ed. J. Sheth. Greenwich, CT: JAI Press, 131-170

${ }^{18}$ Delener, N. 1994. "Religious contrasts in consumer decision behavior patterns: their dimensions and marketing implications." European Journal of Marketing 28: 36-53
} 
iklan produk $^{19}$, atau bahkan mungkin negative mempengaruhi penjualan produk yang diiklankan.

Artikel ini disusun sebagai berikut. Pertama adalah pengenalan singkat ke pandangan dunia Islam. Penjelasan dari kerangka manajerial berikut, yang menunjukkan implikasi dari nilai-nilai Islam untuk pesan iklan. Ilustrasi dalam konteks Timur Tengah, suatu daerah dengan sekitar 275 juta orang dan dengan impor tahunan sebesar lebih dari \$ 150.000.000.000 (Al-Olayan dan 2000 Karande). Bagian akhir artikel termasuk diskusi dan rekomendasi.

\section{B. Kajian Pustaka}

Muslim tidak membedakan antara agama dan sekuler namun Islam menganggap menjadi cara hidup yang lengkap ${ }^{20}$. Kehidupan mereka ini mendapatkan sistem dari ajaran Al Qur'an (Yang dipercaya orang Muslim adalah buku yang diwahyukan oleh Allah kepada Nabi Muhammad pada abad ketujuh Saudi), dan dari sunnah (sabda dicatat dan perilaku Nabi Muhammad). Pandangan dunia Islam didasarkan pada konsep kesejahteraan hidup manusia dan persaudaraan - persaudaraan yang baik dan keadilan sosial ekonomi. Hal ini membutuhkan kepuasan seimbang baik dari kebutuhan material dan spiritual dari semua manusia ${ }^{21}$.

Islam sering disalahpahami, dan ini mengejutkan beberapa yang mengandung sistem sosial ekonomi keseluruhan dengan pedoman khusus untuk mengelola tugas Material seperti iklan. Dalam Islam, kegiatan usaha dianggap menjadi fungsi sosial yang berguna; Nabi Muhammad terlibat dalam perdagangan untuk sebagian besar hidupnya. Sistem sosio-ekonomi Islam mencakup rinci cakupan variabel ekonomi tertentu seperti bunga, perpajakan, sirkulasi kekayaan, perdagangan yang adil, dan konsumsi. Hukum Islam (syari'ah), berasal dari AlQur'an dan sunnah, mengatur hubungan bisnis antara pembeli dan penjual. Kegiatan dikategorikan sebagai sah (halal) atau dilarang (haram), sebagaimana

\footnotetext{
${ }^{19}$ Michell, P. and M. Al-Mossawi. 1999. "Religious commitment related to message contentiousness." International Journal of Advertising

${ }^{20}$ Kavoossi, M. 2000. The Globalization of Business and the Middle East: Opportunities and Constraints. Westport, CT: Quorum Books.

${ }^{21}$ Chapra, M.U. 1992. Islam and the Economic Challenge. Herndon, VA: International Institute of Islamic Thought
} 
ditetapkan oleh Allah. Tidak ada yang haram kecuali apa yang khusus dilarang dalam Al Qur'an atau di jelas otentik, eksplisit sunnah (praktik atau perkataan) Nabi Muhammad.

Sekitar 1,5 miliar penganut agama Islam di seluruh dunia ${ }^{22}$ dan sejumlah besar merupakan konsumen di negara berkembang. Konsumen muslim memiliki daya beli yang besar dan tumbuh di negara-negara seperti Mesir, Iran, India, Malaysia, Maroko, Turki, Saudi Saudi dan Afrika Selatan. Dari "Emerging Markets Sepuluh Besar" sasaran AS Departemen Perdagangan untuk upaya promosi ekspor Amerika, dua adalah negara-negara Muslim (Turki dan Indonesia) dan dua telah substansial Muslim minoritas (India dan Afrika Selatan). Jumlah konsumen Muslim di negara-negara maju juga substansial, seperti di Amerika Serikat, Inggris dan Jerman. Di Perancis, hampir sepersepuluh dari populasi adalah Muslim ${ }^{23}$. Di Amerika Serikat, di mana Islam adalah agama yang paling cepat berkembang, perkiraan kisaran populasi Muslim 6-8.000.000

Kecenderungan di banyak negara dengan mayoritas penduduk Muslim terhadap konservatisme agama lebih kuat dan komitmen ${ }^{24}$. Dampak peningkatan Islam pada operasi bisnis dibuktikan dengan pesatnya pertumbuhan baru-baru ini perbankan dan keuangan Islam seluruh dunia. Sebagai contoh, Citibank memiliki divisi perbankan Islam bermarkas di Bahrain. Dow Jones dan Co telah meluncurkan ekuitas global baru Indeks benchmark (Dow Jones Islamic Market Index) yang bertujuan investor yang mengikuti pedoman investasi Islam $^{25}$. Peningkatan jumlah Muslim ingin berpartisipasi dalam pasar global dengan cara yang konsisten dengan hukum agama Islam. Perkembangan ini menunjukkan agama yang juga dapat memainkan peranan penting dalam beberapa efektivitas strategi komunikasi pemasaran ditargetkan pada umat Islam. Memang, salah satu karakteristik yang membedakan Muslim dari pengikut dari beberapa agama lain

\footnotetext{
${ }^{22}$ Ba-Yunus, I. and M.M. Siddiqui. 1998. A Report on the Muslim Population in the United States of America. New York: Center for American Muslim Research and Information.

${ }^{23}$ Viorst, M. 1996. "The Muslims of France." Foreign Affairs 75: September/October, 78 96

${ }^{24}$ Amin, G. 2000. Whatever Happened to the Egyptians? Cairo: The American University in Cairo Press.

${ }^{25}$ Webb, S. 1999. "Dow Jones Plans to Launch Islamic Market Index." Wall Street Journal (February 8): C12
} 
adalah bahwa pengaruh agama sangat jelas dalam setiap aspek kehidupan Muslim. Dalam sebuah survei di Gulf Cooperation Council (GCC) negara (Bahrain, Kuwait, Oman, Qatar, Arab Saudi dan Uni Emirat Arab), menemukan bahwa sebagian besar responden bersatu dalam keyakinan mereka bahwa struktur kehidupan Islam sehari-hari dari PEO-Gillian Rice dan 77 Al-Mossawi Mohammed Misalnya, dan bahwa masyarakat Teluk dan identitas yang erat ikatan dengan Islam. Sebuah survei dari Mesir menemukan bahwa, setelah kesehatan, agama adalah nilai yang paling penting (Teluk Pemasaran Review Oktober 1996). Menemukan bahwa umat Islam di negara-negara Teluk Arab sering disebut AlQur'an dan Sunnah ketika menjelaskan pentingnya sopan santun dan baik perilaku ${ }^{26}$.

\section{Metode Penelitian}

Penelitian ini menggunakan metode analisis deskriptif yakni suatu metode yang menganalisis data suatu objek kajian, kemudian mendeksripsikannya sesuai hasil analisis data tersebut.

\section{Pembahasan}

Al-Qur'an tidak melarang iklan dan bahwasannya, iklan adalah digunakan untuk mempromosikan agama Islam. Namun demikian, ada beberapa nilai-nilai Islam yang memiliki implikasi penting bagi periklanan. Pada bagian ini, nilai-nilai ini dijelaskan dan mereka implikasi iklan dibahas dan diilustrasikan. dan diskusi disusun berdasarkan empat dimensi budaya: hubungan dengan orang, orientasi waktu, orientasi sifat manusia (konsep diri), dan aktivitas orientasi. Dengan demikian, masing-masing dimensi nilai Islam cocok dengan salah satu kategori ini.

Menurut Kluckhohn dan Strodtbeck ${ }^{27}$, hubungan dari individu untuk orang lain adalah salah satu masalah universal yang dihadapi oleh budaya. Nilai Islam sangat relevan dengan kedua pesan iklan dimensi dan ini dimensi budaya tertentu adalah komunikasi gaya, apresiasi keanekaragaman, keadilan, dan peran

\footnotetext{
${ }^{26}$ MERAC (Middle East Research\&Consultancy) 1987. Arabs as consumers. Research report available from MERAC, P.O. Box 26018, Manama, Bahrain

${ }^{27}$ Kluckhohn, F. and F.L. Strodtbeck. 1961. Variations in Value Orientations. Westport, CT: Greenwood Press.
} 
perempuan. Gaya Komunikasi. Dalam Islam, komunikasi antara orang harus bersikap sopan, baik dan langsung. Nabi Muhammad mengatakan bahwa "Allah menyukai bahwa ketika seseorang melakukan sesuatu, hal itu harus dilakukan dengan baik "28. Ali, salah satu pemimpin awal Islam, kata "yang terbaik wacana ekspresif, bagus, singkat dan menarik "29. Komentar ini menunjukkan bahwa pengiklanan harus berusaha untuk keunggulan sebagai tujuan akhir dalam dirinya sendiri, selain berkomunikasi jujur tentang produk dan jasa.

Pengiklan harus mencatat berlebihan yang dianggap sebagai bentuk berbohong, apakah berlebihan dengan metafora atau dengan menghiasi keterangan. Berlebihan dibolehkan hanya jika berlebihan ini sangat jelas. Kavoossi dan Frank (1990), dalam studi periklanan di Persia Negara-negara Teluk, mengamati kurangnya hiperbola atau berlebihan dibandingkan untuk yang dalam periklanan Amerika. Sebaliknya, mereka mencatat, penekanan berada di lama-lastingness, tradisi, kualitas, dan integritas keseluruhan barang dan penjual. Sebagai contoh, sebuah agen untuk layanan komputer mengklaim "tujuan kita adalah kualitas pelayanan komputer dan tidak menguntungkan."

Iklan Menipu harus dihindari. Perkataan Nabi Muhammad,". . . dia yang menipu tidak salah satu dari kita ${ }^{30}$, dibuat dikonteks insiden penjualan di pasar. Pelajaran dari acara adalah bahwa seorang penjual yang tahu tentang kerusakan dalam sesuatu yang dijualnya berkewajiban untuk mengatakan sebelum penjualan. Ahli hukum Muslim telah didefinisikan penipuan sebagai menyembunyikan cacat yang tidak menonjol kepada masyarakat pada umumnya. Para responden Arab Saudi dalam studi ${ }^{31}$ setuju bahwa pemerintah harus meningkatkan pemantauan klaim iklan.

Agama terminologi dapat digunakan dalam iklan untuk meyakinkan integritas konsumen Islam pada produk dan jasa. Sebagai contoh, dalam iklan

\footnotetext{
${ }^{28}$ Sallam, H. and A.A. Hanafy. 1988. "Employee and employer: Islamic perception." Proceedings of the Seminar on Islamic Principles of Organizational Behavior. Herndon, VA: International Institute of Islamic Thought.

${ }^{29}$ Keller, N.H.M., trans. 1994. Reliance of the Traveller A Classic Manual of Islamic Sacred Law by Ibn Naqib Misri. Evanston, IL: Sunna Books.

${ }^{30}$ Ibid

${ }^{31}$ Al-Makaty, S.S., G.N. Van Tubergen, S.S.Whitlow, and D.A. Boyd. 1996. "Attitudes toward advertising in Islam." Journal of Advertising Research
} 
televisi, sebuah bank investasi Saudi di Mesir meggunakan istilah agama untuk menunjukkan bahwa itu tidak berurusan dengan apapun yang melanggar hukum keuangan islami produk. Penggunaan perintah Alquran yang dipilih dan kata-kata dapat meningkatkan suasana komunikasi periklanan untuk membuatnya lebih menarik bagi konsumen muslim. Contohnya adalah kata-kata "Bismillah" (dengan nama Allah, suatu istilah yang digunakan oleh Muslim sebelum memulai tindakan apapun) atau "Allahu akbar "(harfiah, Allah lebih besar) ${ }^{32}$ memberikan contoh dari produsen pompa air yang menggunakan ayat dari Al Qur'an dalam iklan: "Kami membuat segala sesuatu yang hidup dari air." A Spring 2000 kampanye iklan yang ditargetkan di pasar Teluk untuk Ford Excursion sport utility vehicle menggunakan kata-kata "Ma'ashallah" (apapun yang Tuhan bermaksud). Katakata ini sering digunakan oleh umat Islam ketika mereka melihat sesuatu indah seperti anak kecil, prestasi seseorang seperti mendapatkan gelar atau pekerjaan baru, atau akuisisi seseorang barang baru atau properti. Dalam gaya, optimis bahagia, seorang pria yang lebih muda menunjukkan pria yang lebih tua nya kendaraan baru. Kedua mengenakan pakaian tradisional Teluk. Orang tua menyatakan kata-kata "Ma'ashallah," hanya kata-kata dalam iklan, di berbagai titik dalam pesan: saat pertama melihat kendaraan, ketika melihat seberapa besar itu, ketika mengamati bagaimana melakukan di jalan berbatu di gurun, ketika mengalami kekuatan dan kecepatan, dan akhirnya, ketika melihat pria muda itu keluarga besar (perempuan dalam pakaian tradisional berjilbab) mendapatkan keluar dari kendaraan. Terminologi agama harus digunakan dengan hati-hati. Namun, dalam sebuah studi cakupan Mesir tekan isu iklan 1978-1997, Gillian Rice dan 79 Al-Mossawi Mohammed Keenan dan Shoreh (2000) menemukan cakupan negatif dari iklan secara umum, dan beberapa kritik dari penggunaan yang tidak tepat dari ayat Al Qur'an.

Apresiasi dari Keanekaragaman Ras Manusia. Sebuah fitur mengatakan Islam adalah keragamannya. Nabi Muhammad menekankan kesetaraan ras yang berbeda dan kelompok etnis. Keragaman jelas digambarkan secara komprehensif

\footnotetext{
${ }^{32}$ Luqmani, M., U. Yavas, and Z. Quaraeshi. 1989. "Advertising in Saudi Arabia: content and regulation." International Marketing Review
} 
fotografi catatan Haji (haji) ke Mekah ${ }^{33}$. Keanekaragaman ada dalam populasi beberapa negara seperti yang ada di kawasan Teluk yang memiliki populasi Muslim besar ekspatriat. Dalam pelaksanaan periklanan, keanekaragaman harus diakui, seperti dalam sebuah IKEA iklan yang menunjukkan orang-orang dari berbagai kelompok etnis, dan beberapa dalam pakaian tradisional dan beberapa dalam pakaian Barat. Keanekaragaman digunakan sebagai alat posisi oleh Gulf Air dalam kampanye cetak lokal dan di seluruh dunia. Iklan Cetak berlari di media global, seperti majalah The Economist, dan menampilkan foto tersenyum Air Teluk mewakili banyak kelompok karyawan yang berbeda etnis.

Meskipun pengakuan Islam tentang keragaman dan nasihat Al-Quran bahwa tidak ada paksaan dalam agama, perusahaan multinasional Asea Brown Boveri tidak diizinkan untuk menggunakan logo ABB saat mendaftar untuk beriklan di Bahrain Airport. Gambar 2 menunjukkan logo ABB (huruf merah di latar belakang putih). Gambar 3 menunjukkan satu-satunya bentuk diterima logo, sedangkan "Salib" ( dimata muslim, mungkin mengingatkan pada salib Kristen) disarankan memotong garis melalui pusat-pusat surat yang keluar sudah diblokir ${ }^{34}$.

Hukum dan Keadilan. Kepatuhan terhadap prinsip-prinsip keadilan dan kewajaran ditafsirkan dalam konteks Timur Tengah berarti sedikit ada terus terang pesan iklan komparatif ${ }^{35}$. Sebagai contoh, sebuah iklan untuk pengatur suhu udara York dibandingkan untuk pendingin udara Jepang, mereka diproduksi tetapi tidak untuk bersaing merek.

Kewajiban kontrak, menurut tradisi Islam, harus dikenakan sanksi oleh Allah. Iklan yang mengandung janji, syarat dan kontrak lainnya sehubungan

\footnotetext{
${ }^{33}$ Nomachi, A.K. 1997. Mecca the blessed Medina the radiant. Hong Kong: Odyssey Books.Onkvisit, S. and J.J. Shaw. 1999. "Standardized international advertising: Some research issues and implications." Journal of Advertising Research 39: 19-24.

${ }^{34}$ Al-Mohamed, F.F. 1997. Personal interview with Fathi Al-Mohamed, Managing Director, Gulf Media International, P.O. Box 10688, Manama, Bahrain

${ }^{35}$ Razzouk, N. and J. Al-Khatib. 1993. "The nature of television advertising in Saudi Arabia: content analysis and marketing implications." Journal of International Consumer Marketing
} 
dengan transaksi bisnis atau keuangan karena sering termasuk frase konvensional "dengan nama Allah, Paling Pemurah, lagi Maha Penyayang "36.

Menurut Al-Qur'an dan sunnah, akuisisi pengetahuan merupakan kewajiban bagi semua Muslim, perempuan maupun laki-laki. Hal ini percaya bahwa perempuan harus dididik karena tanggung jawab mereka dalam membesarkan anak. Hal ini juga diperbolehkan bagi wanita untuk bekerja di luar rumah. Meskipun sebagian besar perempuan yang bekerja di Arab Saudi dan Qatar cenderung mengikuti karir tradisional seperti kesehatan dan pendidikan, tren perubahan di negara-negara Teluk kurang-konservatif. Misalnya, perempuan lebih dibandingkan lulusan laki-laki di UAE, Kuwait dan Oman (Thomas 1998). perempuan Bahrain adalah bagian dari kehidupan sehari-hari di kantor Manama. Pengunjung kementerian, sektor swasta, sekolah-sekolah dan perguruan tinggi di Kuwait akan bertemu wanita nasional senior. Oman memiliki dua menteri perempuan. Meskipun perkembangan tersebut, Thomas (1998) menulis bahwa Teluk perempuan "Melayani ekstrem iklan yang lama sama bahwa pasar dunia lain bertahan di tahun tujuh puluhan: glamour (Cindy Crawford, Claudia Schiffer, Naomi dan Mesir menari perempuan) di satu sisi, wastafel dapur, di lain"37 berpendapat bahwa tidak ada gambar perempuan serius dalam iklan, dan komentar yang banyak dalam iklan perbankan, wanita sering menunjukkan bahwa suami punya uang-itu bukan uang dia, namun dalam kenyataannya wanita sign up untuk saling dana, pembukaan rekening mereka sendiri, dan penandatanganan cek sendiri. Meskipun demikian, iklan pada Gambar 4 untuk Bank Nasional Bahrain yang menggunakan menarik bagi keluarga dan kebutuhan untuk menabung untuk pendidikan anak-anak menyiratkan bahwa ibu terlibat dalam keputusan dan menunjukkan kedua anak laki-laki dan seorang gadis sebagai anak-anak memprihatinkan. Sebuah Mercedes kampanye di Arab tekan perempuan

\footnotetext{
${ }^{36}$ Kavoossi, M. and J. Frank. 1990. "The language-culture interface in Persian Gulf States print advertisements: implications for international marketing." Journal of International Consumer Research

${ }^{37}$ Thomas, K. 1998. "Between Cindy and the kitchen sink." Gulf Marketing Review 49: 24-29
} 
menekankan keselamatan mobil, mengakui bahwa banyak Teluk wanita pemilik mobil di kanan mereka sendiri atau setidaknya, memainkan peran kunci dalam memilih mobil keluarga. Dalam sebuah iklan TV Saudi untuk L'Oreal Kepenuhan (produk perawatan kulit), perempuan ditampilkan dalam pendidikan terkait pengaturan dan bekerja dengan komputer.

kekhawatiran orientasi waktu terhadap perspektif budaya di aspek temporal kehidupan manusia seperti sikap terhadap tradisi dan masa lalu, sejauh mana orang menerima situasi sekaran dan tingkat perencanaan untuk masa depan. Konsumsi perilaku dan tingkat materialisme dalam masyarakat adalah cerminan dari orientasi waktu karena dapat menunjukkan apakah orang yang relatif lebih terfokus pada " hidup duniawi ini "atau pada" kehidupan setelahnya. "

Konsumsi seimban, membedakan antara "materialisme instrumental" dan "materialisme terminal ${ }^{38}$." Dalam materialisme instrumental, objek yang dihargai karena kemampuan mereka untuk membantu melakukan aktivitas tertentu. Dalam materialisme terminal, objek dinilai sebagai tujuan dalam diri mereka dan kepemilikan dicari hanya demi memiliki objek. Dari perspektif Islam, instrumental materialisme diterima tetapi materialisme terminal tidak. Nabi Muhammad disarankan umat Muslim untuk menjadi moderat dalam semua urusan mereka; ia menggambarkan Islam adalah "jalan tengah." Islam bukan agama pertapa. Hal ini memungkinkan orang untuk memenuhi kebutuhan mereka dan melampaui. Gambar 5 adalah iklan untuk sebuah merek jam tangan mewah yang menggambarkan romantisme dan menggunakan budaya gambar diterima tradisi dan kesopanan.

Kesederhanaan dalam konsumsi dapat dicapai dalam gaya hidup bersama kreativitas dan keragaman, bagaimanapun, dan Islam menekankan berbagi kekayaan di antara sesama Muslim. Tanggung jawab sosial lebih disukai untuk konsumsi dan laba-mencari. Banding terhadap perekonomian rumah tangga dan kesempatan untuk menyimpan sering terjadi. Contoh ditunjukkan pada Gambar 6. The Pesan dalam iklan cetak Pepsi adalah bahwa konsumen dapat menyimpan

${ }^{38}$ Csikszentmihalyi, M. and E. Rochberg-Halton. 1981. Reflections on Materialism. University of Chicago Magazine 
dengan Pepsi dan didorong untuk minum Pepsi pada saat buka puasa selama bulan Ramadhan. Sebuah iklan untuk popok Luvs ditampilkan pada Saluran satelit Arab MBC berfokus pada menyimpan uang. Seorang wanita secara penuh Pakaian Islami menjelaskan bahwa dia memiliki keluarga besar dan karenanya harus prihatin tentang tabungan, harga Luvs adalah wajar. Pada akhir iklan, koin yang menumpuk selain paket popok Luvs dan voice-over bernyanyi "melakukan penghematan."

Sebuah promosi harga-off Coca-Cola-diiklankan memiliki konsekuensi yang tidak diinginkan, namun. Untuk merayakan tahun pertama di pasar Iran, Coca-Cola Company diiklankan sebuah promosi diskon harga minuman kemasan lembut. Bertentangan dengan niatnya, mengakibatkan banyak yang mempertanyakan margin keuntungan perusahaan untuk tahun sebelumnya dan menyebabkan kritik yang mengakibatkan larangan kampanye. Pada bulan Juni 1994, pemerintah memberlakukan harga jual pada semua minuman ringan yang tampaknya lebih rendah dari biaya produksi untuk kedua Coke dan Pepsi ${ }^{39}$.

Apresiasi Pendidikan / Science. Muslim memiliki orientasi yang kuat terhadap tradisi. Mereka percaya bahwa kehidupan-sistem yang dianjurkan dalam Al-Qur'an dan sunnah adalah berlaku untuk semua waktu dan tempat. Selain itu, umat Islam sangat bangga dengan prestasi ilmiah dan intelektual mereka yang lain di abad pertengahan dan, sebagai orang, mereka terus menjadi pendukung kuat pendidikan. Dibanding iklan yang mencakup pengakuan terhadap pentingnya pendidikan dan kerja ilmiah baik dengan konsumen Muslim.

Karakter sifat manusia adalah salah satu dimensi budaya diidentifikasi oleh Kluckhohn dan Strodtbeck (1961). Usunier (1993) secara khusus menggambarkan hal ini sebagai "konsep diri dan konsep orang lain." berfokus Bagian ini pada kesederhanaan, yang merupakan diri yang sangat penting dan konsep yang dikehendaki atau ciri karakter dalam Islam.

Kesopanan. Gilly (1988) berpendapat bahwa iklan harus mencerminkan budaya dan bahwa dalam hal peran seks, itu harus mencerminkan norma-norma

\footnotetext{
${ }^{39}$ Shargh, M. 1994. “Iran’s Advertising Revival.” Gulf Marketing Review (December): 32-36.
} 
budaya seks itu. Beragam praktik di negara-negara Muslim mencerminkan pengaruh budaya. Ada kesenjangan yang besar antara ideal Islam dan budaya nyata. Kedua ekstrem ada dari pengasingan perempuan lengkap untuk terbatas pencampuran jenis kelamin. Namun parameter dari kerendahan hati yang tepat untuk kedua pakaian laki-laki dan perempuan dan perilaku dipandang sebagai pedoman ilahi didasarkan dengan tujuan yang sah, bukan pembatasan yang dikenakan laki-laki atau masyarakat yang dipaksakan.

Sehubungan dengan pakaian perempuan, Al Qur'an menyebutkan bahwa perempuan tidak boleh "pamer perhiasan mereka kecuali yang nyata." Beasiswa telah menafsirkan ini secara berbeda kebanyakan sarjana mengacu sunnah dan menafsirkan ayat ini bahwa perempuan bisa menunjukkan hanya tangan dan wajah laki-laki di luar lingkaran keluarga dekat mereka. Sebuah penafsiran ketat adalah bahwa perempuan harus benar-benar berjilbab.

Karena penafsiran dan berbeda sikap, variasi iklan dapat diharapkan dalam penggambaran perempuan dalam iklan. Al-Makaty et al ${ }^{40}$ menyediakan teks Arab Saudi Kementerian Informasi pedoman untuk iklan televisi: "Prinsip-prinsip utama terdiri dari pengamatan yang benar dari iman Islam, ajaran Islam dan kepercayaan yang fundamental yang dikenakan nilai tinggi bagi manusia, kehidupan dan perilaku pribadi dan sosial individu "menggambarkan. Saudi TV iklan perempuan yang biasanya berkerudung, hanya menampilkan wajah dan tangan mereka. Dalam analisis isi iklan majalah pan-Arab, Mesir, Libanon dan Emirat, Al-Olayan dan Karande (2000) menemukan bahwa 83 persen dari iklan Arab yang menunjukkan perempuan, mereka mengenakan pakaian panjang, dibandingkan dengan 29 persen dalam iklan AS. Selain itu, penelitian mereka menunjukkan bahwa Arab lebih menunjukkan iklan perempuan dalam iklan ketika kehadiran mereka berkaitan dengan produk yang diiklankan dibandingkan iklan Amerika.

Iklan tradisional Barat mencoba untuk menyembunyikan kurangnya diferensiasi merek dengan berinvestasi dengan kualitas seperti gengsi dan daya

\footnotetext{
${ }^{40}$ Al-Makaty, S.S., G.N. Van Tubergen, S.S.Whitlow, and D.A. Boyd. 1996. "Attitudes toward advertising in Islam." Journal of Advertising Research
} 
tarik seks ${ }^{41}$. Hal ini lebih sulit untuk menggunakan daya tarik seks untuk membedakan produk mana hambatan hukum atau budaya seperti yang ada dijelaskan di atas. Sebuah iklan billboard untuk parfum Davidoff Cool Air itu, di negara lain, menunjukkan seorang wanita telanjang tampaknya muncul dari danau, diadaptasi untuk Bahrain. Foto ini diubah sehingga bahu model tertutup, ia kemudian tampaknya muncul dari belakang batu di danau dan hanya wajahnya terlihat (lihat Gambar 7). Iklan masih mengangkat keluhan dari pemerintah kota di Bahrain, namun. ekspresi wajah Model itu digambarkan sebagai "terlalu seksi dan mengundang" 42 .

Close-Up pasta gigi secara tradisional telah diposisikan atas dasar daya tarik seks. Sebuah iklan untuk Close-Up ditunjukkan di negara-negara Teluk pada tahun 1997 disesuaikan tema ini untuk masyarakat ini lebih konservatif dalam cara yang sangat kreatif. Beberapa orang pemuda gembira pergi ke mal, sedangkan berjalan di sana, mereka melewati sekelompok kecil perempuan muda, salah satunya terjatuh saputangan. Salah satu pemuda mengambil saputangan itu dan memberikan kepada wanita muda sambil tersenyum. Tidak ada kontak fisik antara mereka, dan perlu dicatat bahwa situasi ini digambarkan spontan terjadi dan bukan sebagai acara kencan berorientasi Barat. Luqmani menggambarkan bagaimana, di Arab Saudi, pengiklan kosmetik menahan diri dari membayangkan perempuan sensous. Sebaliknya, dalam iklan yang khas (contoh adalah pembersihan bar Dove), seorang wanita yang senangkan yang tampak muncul di jubah dan hiasan kepala hanya dengan menunjukkan wajahnya. Karakter kartun untuk mewakili perempuan cenderung melanggar kode Islam. Namun, perawatan harus dilakukan. Tak lama setelah Mattel membuka kantor regional baru di Dubai, seorang imam Kuwait memberlakukan "fatwa" (penguasa agama) pada boneka Mattel Barbie, dan sumber-sumber agama di Iran mengecam boneka memiliki efek tidak sehat pada pikiran dan moral anak-anak muda.

\footnotetext{
${ }^{41}$ Ibid

${ }^{42}$ Al-Mohamed, F.F. 1997. Personal interview with Fathi Al-Mohamed, Managing Director, Gulf Media International, P.O. Box 10688, Manama, Bahrain.
} 
Iklan kondom sangat sulit dalam masyarakat konservatif. Pendekatan di Mesir, di mana target adalah keluarga dan pesan keluarga berencana, kontras dramatis dengan kampanye 1998 iklan agak bersifat cabul dikembangkan oleh McCann-Erickson untuk kondom Durex, menargetkan para lajang muda dan berjalan di Eropa. Di Mesir, eksekusi iklan untuk sebuah merek kondom menunjukkan seorang ayah dan ibu memperkenalkan diri dan anak-anak mereka dengan cara yang penuh kasih. Pesan, dijelaskan oleh orang tua, adalah bahwa hanya memiliki dua anak, jarak beberapa tahun terpisah, berarti bahwa seseorang dapat menghabiskan waktu dan perhatian merawat mereka. Iklan kondom adalah topik yang sangat sensitif, baik dalam konteks keluarga berencana atau perawatan kesehatan preventif.

Di Bahrain, dianggap sebagai salah satu negara-negara Teluk lebih liberal, iklan kontrasepsi dilarang (lihat Tabel 2 untuk Teluk Media International Code of Acceptance). Produk lain juga dapat dikenakan pembatasan karena keinginan untuk menjaga kesopanan dalam masyarakat. Sebagai contoh, sebuah perusahaan Korea diterapkan untuk izin untuk mengiklankan produk pakaian dalam lokasi bandara Bahrain. iklan itu dapat diterima hanya jika kata-kata "Best Cotton Underwear" dihapus; lihat Gambar 8, yang menunjukkan teks menyinggung dicoret $^{43}$.

Setelah revolusi Iran, iklan televisi pergi melalui tiga tahap: (1) iklan mengandalkan sepenuhnya pada suara dan beberapa gambar diam, (2) iklan dengan menggunakan suara dan gambar kartun, dan (3) iklan dengan karakter suara dan hidup. Dalam semuaiklan ini, wanita yang mengenakan busana Islam penuh. Secara khusus, iklan Iran ditandai dengan proporsi yang lebih tinggi dari laki-laki dan anak-anak daripada perempuan yang muncul dalam iklan, musik sedikit atau tidak ada, dan fokus yang kuat pada keluarga.

Usunier $^{44}$ penjelasan orientasi kegiatan, atau "sikap budaya's terhadap tindakan, "termasuk hubungan manusia dengan alam. Peduli Lingkungan dan

\footnotetext{
${ }^{43}$ Al-Mohamed, F.F. 1997. Personal interview with Fathi Al-Mohamed, Managing Director, Gulf Media International, P.O. Box 10688, Manama, Bahrain.

${ }^{44}$ Usunier, J. 1993. International Marketing A Cultural Approach. Prentice Hall International (UK) Limited.
} 
Kesehatan. Perspektif Islam terhadap lingkungan adalah bahwa manusia wali lingkungan. Semuanya orang memiliki (bahkan tubuh seseorang) adalah milik Allah dan karena itu orang harus merawat diri, harta mereka dan lingkungan pada umumnya. Perilaku boros adalah dikutuk dalam Al Qur'an. Implikasi dari ini adalah bahwa konsumen muslim harus siap menanggapi banding iklan yang ramah kebersihan, lingkungan dan kesehatan. Pada kenyataannya, karena kondisi ekonomi, negara-negara Muslim, bersama dengan sebagian besar negara-negara berkembang lainnya, lebih lambat untuk mengadopsi peraturan lingkungan daripada negara-negara maju. Namun demikian, saat ini ada peluang yang cukup untuk pesan iklan lingkungan. Sebagai contoh, di Bahrain, Al-Jazira Supermarket logo tempat lingkungan terhadap tas plastik belanja dengan frase "Perlindungan Lingkungan Hidup adalah Tugas Nasional kita." Juga di Bahrain, Nada Air Mineral diposisikan sebagai ramah lingkungan dan sehat karena botol plastik yang bening, yang berbeda dengan botol plastik biru para pesaingnya.

Sebagaimana disyariatkan umat Islam dilarang mengkonsumsi daging yang belum disembelih dengan cara halal atau "halal", serta minuman keras seperti anggur. Banyak restoran dan rantai makanan cepat saji di Timur Tengah (seperti Pak Wimpy, Burger King, McDonald's, Hardee's dan Dairy Queen) mengiklankan bahwa makanan mereka adalah "dijamin halal." Sebuah hotel Hilton iklan cetak untuk "Jumat Brunch" dan "Rabu Steak Night "menekankan pada bahwa daging adalah" Real Halal.

\section{E. Kesimpulan}

Di Timur Tengah, ada pertumbuhan yang kuat di belanja iklan dan dalam upaya untuk menempatkan iklan dalam memperluas dan mengembangkan media penyiaran dan cetak (misalnya, lihat Westcott 1998, Martin 1998, dan Timur Tengah Eksekutif Laporan 1998). Namun, dalam survei global sikap terhadap iklan di 22 negara, Timur Tengah besar pasar, Mesir, adalah satu-satunya negara di mana responden secara konsisten anti-iklan ${ }^{45}$. Penjelasan dari hasil ini oleh

\footnotetext{
${ }^{45}$ Wentz, L. 1993. "Major global study finds consumers supports ads." Advertising Age International. October 11: 1
} 
sponsor survei, Asosiasi Internasional Pengiklan, termasuk tumbuh ekstremisme religius. Oleh karena itu, sehubungan dengan pengembangan pesan, eksekutif di perusahaan iklan untuk konsumen Muslim di Timur Tengah dan di tempat lain akan lebih bijaksana untuk memperoleh pemahaman tentang nilai-nilai Islam.

Holbrook $^{46}$ berpendapat bahwa, karena produk yang paling banyak dalam tahap dewasa dari siklus hidup mereka, menambah atau keyakinan orang reposisi adalah lebih bermanfaat daripada mencoba untuk mengubah kriteria pilihan mereka atau mencoba untuk memindahkan titik ideal mereka. Kriteria pilihan tersebut dan titik ideal berlabuh dalam sistem nilai yang merupakan hasil dari sosialisasi jangka panjang yang luas. Dengan demikian, iklan harus berusaha untuk mencerminkan nilai-nilai suatu masyarakat. Sebagai Michell dan AlMossawi ${ }^{47}$ berpendapat titik penting untuk memanipulasi unsur-unsur iklan yang dapat membuktikan perdebatan (seperti jenis musik tertentu, citra seksual, dibandingkan dengan merek bernama lain, berlebihan, dll) untuk memperkuat komunikasi pesan sementara tetap mempertahankan integritas dari strategi iklan dan elemen-elemen yang sesuai nilai-nilai target.

Hal ini tidak selalu mudah, namun, untuk mencocokkan iklan ke nilai target konsumen merupakan tantangan mengidentifikasi nilai-nilai. Sebagai contoh, De Mooij ${ }^{48}$ membahas nilai paradoks di mana orang bisa membedakan antara keinginan apa yang dipikirkan orang seharusnya dan apa yang benar-benar orang inginkan, atau bagaimana orang berpikir dunia seharusnya dengan apa yang orang inginkan untuk diri mereka sendiri. The "diinginkan" mengacu pada normanorma umum masyarakat dan worded dalam hal benar atau salah, misalnya beberapa dimensi nilai Islam (seperti kejujuran, keadilan dan kerendahan hati) tercantum dalam Tabel 1 yang dirumuskan dalam hal "diharapkan." dan "yang diinginkan" adalah apa yang orang inginkan untuk diri mereka sendiri dan apa

\footnotetext{
${ }^{46}$ Holbrook, M.B. 1987. "Mirror, mirror, on the wall, what's unfair in the reflections on advertising." Journal of Marketing

${ }^{47}$ Michell, P. and M. Al-Mossawi. 1995. "The mediating effect of religiosity on advertising effectiveness." Journal of Marketing Communications

${ }^{48}$ De Mooij, M. 1998. Global Marketing and Advertising. Thousand Oaks, CA: Sage Publications, Inc.
} 
yang mayoritas orang-orang di suatu negara benar-benar melakukannya. Rice ${ }^{49}$, dalam nada yang sama, mengidentifikasi nilai-nilai Islam dengan praktek aspirasional sehari-hari di Mesir, sebuah negara yang penduduknya adalah mayoritas Muslim.

Ada berbagai segmen konsumen yang diragukan dapat diidentifikasi dengan menggunakan religiusitas sebagai dasar segmentasi. Segmen ini dapat ditemukan baik di dalam dan di negara-negara Timur Tengah. Segmen dapat diambil pada sebuah kontinum dari kurang konservatif (berfokus pada "yang diinginkan" dan pragmatis) untuk lebih konservatif atau Islam-dominan (menekankan "diinginkan" atau ideal). Perlu dicatat bahwa penerimaan nyata dari simbol-simbol konsumerisme Barat tidak berarti penerimaan nilai-nilai Barat. Suatu 1997 studi penelitian yang dilakukan oleh Fortune Promoseven di Arab Saudi dan UEA menemukan bahwa laki-laki muda merangkul teknologi dan konsumerisme, mereka mengejutkan konservatif ${ }^{50}$. Juga Muslim, bahkan nonpraktisi sering memiliki identitas Islam yang kuat dan akan tertarik oleh banding berorientasi islami. Kolektivis (dan Muslim masyarakat yang kolektif bukan individualis) dapat menangani lebih banyak perbedaan antara sikap dan perilaku daripada yang dapat individualis (Gentry et al 1995.). Memanfaatkan kekuatan kadang-kadang bertentangan dengan tradisi dan eksplorasi, yang muncul sebagai kunci emosional sungai dari studi Arab Saudi (Jordan 1998), karena itu merupakan tantangan yang kuat bagi pengiklan, tidak hanya di Arab Saudi, tetapi di seluruh wilayah Timur Tengah. Studi tentang remaja Saudi dan keluarga muda Saudi yang dilakukan oleh lembaga penelitian Merlin ${ }^{51}$ menyimpulkan bahwa remaja di Arab Saudi berbeda dari rekan-rekan global mereka di sejumlah daerah yang signifikan. Mereka merasa aman dalam sistem kesejahteraan keluarga besar mereka. Menghormati antara remaja dan orang tua mereka muncul bersama. Hanya enam persen dari remaja yang disurvei "sangat setuju" bahwa orang tua mereka sering malu di depan teman-teman mereka. Ditanyakan pertanyaan yang

\footnotetext{
${ }^{49}$ Rice, G. 1999. "Islamic ethics and the implications for business.” Journal of Business Ethics

${ }^{50}$ Thomas, K. 1997. "Who do we think we are?" Gulf Marketing Review

${ }^{51}$ Jordan, B. 1998. "Kid's stuff?” Gulf Marketing Review
} 
sama, 58 persen remaja di Inggris setuju dengan pernyataan itu. Perbedaan ini ditandai, dan lain-lain yang sifatnya serupa, memiliki implikasi yang menarik untuk penggunaan model peran aspiratif dalam iklan dan promosi. Dukungan keluarga meningkatkan dan mendukung diri para remaja Saudi '-harga diri dan kepercayaan diri. Studi ini juga menemukan bahwa remaja Saudi tidak berusaha untuk memakai "lencana" yang mengidentifikasikan mereka dengan budaya Barat. Badan Penelitian Merlin merekomendasikan bahwa ada peluang bagi merek tetapi tidak untuk citra Amerika atau global memaksa ke pasar yang memiliki keyakinan yang mendalam dalam keunggulan budaya sendiri dan masyarakat.

\section{Daftar Pustaka}

Rahman, Abdul, Y.K. and A.S. Tug. 1998. "LARIBA (Islamic) Mortgage Financing in the United States." Proceedings of the Second Harvard University Forum on Islamic Finance, October 9-10, Cambridge, MA: Harvard University.

Al-Makaty, S.S., G.N. Van Tubergen, S.S.Whitlow, and D.A. Boyd. 1996. "Attitudes toward advertising in Islam." Journal of Advertising Research.

Al-Mohamed, F.F. 1997. Personal interview with Fathi Al-Mohamed, Managing Director, Gulf Media International, P.O. Box 10688, Manama, Bahrain.

Al-Olayan, F.S. and K. Karande. 2000. "A content analysis of magazine advertisements from the United States and the Arab World." Journal of Advertising.

Amin, G. 2000. Whatever Happened to the Egyptians? Cairo: The American University in Cairo Press.

Ba-Yunus, I. and M.M. Siddiqui. 1998. A Report on the Muslim Population in the United States of America. New York: Center for American Muslim Research and Information.

Boddewyn, J.J. 1982. "Advertising regulation in the 1980s: the underlying global forces." Journal of Marketing Winter.

Chapra, M.U. 1992. Islam and the Economic Challenge. Herndon, VA: International Institute of Islamic Thought.

Csikszentmihalyi, M. and E. Rochberg-Halton. 1981. Reflections on Materialism. University of Chicago Magazine.

Delener, N. 1994. "Religious contrasts in consumer decision behavior patterns: their dimensions and marketing implications." European Journal of Marketing. 
De Mooij, M. 1998. Global Marketing and Advertising. Thousand Oaks, CA: Sage Publications, Inc.

Duncan T. and J. Ramaprasad. 1995. "Standardized multinational advertising: the influencing factors." Journal of Advertising.

Geertz, C. 1973. The Interpretation of Cultures. New York: Basic Books.

Gentry, J.W., S. Jun, and P. Tansuhaj. 1995. "Consumer acculturation processes and cultural conflict." Journal of Business Research.

Gilly, M.C. 1988. "Sex roles in advertising: a comparison of television advertisements in Australia, Mexico and the United States." Journal of Marketing 52 (April).

Gould, S.J. 1995. "The Buddhist perspective on business ethics: experiential exercises for exploration and practice." Journal of Business Ethics.

Gulf Marketing Review. 1996. “Iranians slam ‘Satanic’ Barbie.” 25 (June).

Gulf Marketing Review. 1996. "Delving into Egyptian values." 29 (October).

Hill, J.S. and W.L. James. 1990. "Effects of selected environmental and structural factors on international advertising strategy: an exploratory study." Current Issues and Research in Advertising.

Hirshman, E.C. 1981. "American Jewish ethnicity: its relationship to some selected aspects of consumer behavior." Journal of Marketing 45 (Summer).

Hischman, E.C. 1984. "Religious affiliation and consumption processes." In Research in Marketing. Ed. J. Sheth. Greenwich, CT: JAI Press.

Holbrook, M.B. 1987. "Mirror, mirror, on the wall, what's unfair in the reflections on advertising." Journal of Marketing.

Jordan, B. 1998. “Kid's stuff?” Gulf Marketing Review.

Kavoossi, M. 2000. The Globalization of Business and the Middle East: Opportunities and Constraints. Westport, CT: Quorum Books.

Kavoossi, M. and J. Frank. 1990. "The language-culture interface in Persian Gulf States print advertisements: implications for international marketing." Journal of International Consumer Research.

Keenan, K.L. and B. Shoreh. 2000. "How advertising is covered in the Egyptian press: a longitudinal examination of the content." International Journal of Advertising.

Keller, N.H.M., trans. 1994. Reliance of the Traveller A Classic Manual of Islamic Sacred Law by Ibn Naqib Misri. Evanston, IL: Sunna Books.

Keng, K.A. and C. Yang. 1993. "Value choice, demographics, and life satisfaction." Psychology and Marketing. 
Kluckhohn, F. and F.L. Strodtbeck. 1961. Variations in Value Orientations. Westport, CT: Greenwood Press.

Laroche, M., V.H. Kirpalani, F. Pons and L. Zhou. 2001. "A model of advertising standardization in multinational corporations." Journal of International Business Studies.

Lawrence, B.B. 1998. Shattering the Myth: Islam Beyond Violence. Princeton, NJ: Princeton University Press.

Luqmani, M., U. Yavas, and Z. Quaraeshi. 1989. "Advertising in Saudi Arabia: content and regulation." International Marketing Review 6.

Martin, M. 1998. "Middle East print matures.” Campaign (May 8).

McDaniel, S.W. and J.J. Burnett. 1990. "Consumer religiosity and retail store evaluative criteria." Journal of the Academy of Marketing Science.

Melewar, T.C., S. Turnbull and G. Balabanis. 2000. "International advertising strategies of multinational enterprises in the Middle East." International Journal of Advertising.

MERAC (Middle East Research\&Consultancy) 1987. Arabs as consumers. Research report available from MERAC, P.O. Box 26018, Manama, Bahrain.

Michell, P. and M. Al-Mossawi. 1995. "The mediating effect of religiosity on advertising effectiveness." Journal of Marketing Communications.

Michell, P. and M. Al-Mossawi. 1999. "Religious commitment related to message contentiousness." International Journal of Advertising.

Middle East Executive Reports 1998. "Egyptian spending on advertising growing 30 percent a year as reforms begin to move through economy." 21 (August).

Nomachi, A.K. 1997. Mecca the blessed Medina the radiant. Hong Kong: Odyssey Books.Onkvisit, S. and J.J. Shaw. 1999. "Standardized international advertising: Some research issues and implications." Journal of Advertising Research 39.

Qur'an. Undated. English translation of the meaning. Revised version of translation by Abdallah Yusuf Ali. Saudi Arabia: The Presidency of Islamic Researches, King Fahd Holy Qur'an Printing Complex.

Razzouk, N. and J. Al-Khatib. 1993. "The nature of television advertising in Saudi Arabia: content analysis and marketing implications." Journal of International Consumer Marketing.

Rice, G. 1999. "Islamic ethics and the implications for business." Journal of Business Ethics.

Ricks, D.A. 1993. Blunders in International Business, Cambridge, MA: Blackwell Publishers. 
Rossauw, G.J. 1994. "Business ethics: where have all the Christians gone?" Journal of Business Ethics 13.

Sallam, H. and A.A. Hanafy. 1988. "Employee and employer: Islamic perception." Proceedings of the Seminar on Islamic Principles of Organizational Behavior. Herndon, VA: International Institute of Islamic Thought.

Shargh, M. 1994. "Iran's Advertising Revival.” Gulf Marketing Review (December).

Thomas, K. 1997. "Who do we think we are?” Gulf Marketing Review.

Thomas, K. 1998. "Between Cindy and the kitchen sink." Gulf Marketing Review.

Tse, D., L. Kam-Hon, I. Vertinsky and D. Wehrung. 1988. "Does culture matter? A cross-cultural study of executives' choice, decisions and risk adjustment in international marketing." Journal of Marketing 52.

Viorst, M. 1996. "The Muslims of France." Foreign Affairs 75: September/October.

Usunier, J. 1993. International Marketing A Cultural Approach. Prentice Hall International (UK) Limited.

Wafai, M. and J. El-Tigi. 1996. "Egyptian consumers: toward a more comprehensive socio-demographic and psychographic segmentation system." In Pressure on Profit: Challenge for Research? Proceedings of 3rd ESOMAR/MERF/IAA Middle East and North Africa Conference. Amsterdam:ESOMAR.

Webb, S. 1999. "Dow Jones Plans to Launch Islamic Market Index." Wall Street Journal (February 8): C12

Wentz, L. 1993. "Major global study finds consumers supports ads." Advertising Age International. October 11: 1.

Westcott, K. 1998. "The battle for the Arab satellite market." Campaign (May 8). 